\title{
Increasing hospital admission rates and economic burden for colorectal cancer in Brazil, 1996-2008
}

\author{
Ulysses dos Santos Torres, ${ }^{1}$ Thomas Eugenio Portes de Almeida, ${ }^{1}$ \\ and João Gomes Netinho'
}

Suggested citation Torres US, Almeida TEP, Netinho JG. Increasing hospital admission rates and economic burden for colorectal cancer in Brazil, 1996-2008. Rev Panam Salud Publica. 2010;28(4):244-8.

\begin{abstract}
Objective. To determine the trends in hospital admission rates for colorectal cancer (CRC) in the Brazilian Public Health System from 1996 to 2008 and to assess the economic costs. Methods. Data from the Hospital Information Systems database of the Brazilian Unified Health System were used for analysis of all admissions with a primary diagnosis of CRC between 1996 and 2008.

Results. There were 297108 CRC admissions over the study period, with an annual increase from 12821 in 1996 to 35040 in 2008. Age-standardized admission rates increased from 8.7 to 23.56 per 100000 for a percentage increase of $171 \%$. The average length of stay decreased from 11.6 days in 1996 to 7.5 days in 2008. The average hospital mortality declined from $10.4 \%$ to $8.5 \%$. Overall costs in United States dollars (US\$) of CRC hospitalizations rose from US\$16.5 million in 1996 to US\$33.5 million in 2008; the average cost of each admission, however, decreased from US\$ 1283 to US\$ 954.

Conclusions. Hospitalization rates for CRC in Brazil significantly increased during a 13year period, incurring a considerable rise in the inflation-adjusted economic burden; national in-hospital mortality rates have remained relatively high.
\end{abstract}

Key words Colorectal neoplasms; hospitalization; length of stay; hospital mortality; hospital costs; Brazil.

Colorectal cancer (CRC) is the third most common malignancy in the world in both men and women and it is the fourth leading cause of cancer-related death. Incidence rates of CRC worldwide are remarkably variable. The highest rates are found in developed countries, including the United States, Canada, Australia, and the countries of northwestern Europe. A comparatively low rate is observed in

\footnotetext{
1 Department of Surgery, São José do Rio Preto Medical School, São José do Rio Preto, Brazil. Send correspondence to João Gomes Netinho, jgnetinho@ riopreto.com.br
}

Asian, African, and South America countries, although incidence rates are increasing in countries that were previously considered low incidence (1).

The International Agency for Research on Cancer estimated that CRC was the fourth most common form of cancer in men and third in women for the year 2008 in Latin America (1); CRC was also the fourth most frequent cause of cancerrelated death in men and fifth in women (1). In Brazil, for 2008, CRC was the fourth most frequent malignancy, with approximately 13000 new cases estimated in males and 14500 in females $(2,3)$.
Unfortunately, there are few studies on the epidemiology of CRC in Latin America and, specifically, in Brazil. Nevertheless, current data indicate that the incidence of CRC and its related mortality has increased in the country in recent decades, especially in the more developed and industrialized regions (4-6). An average annual growth of $3.5 \%$ in CRC deaths was reported between 1979 and 2000, from 2.44 to 4.12 per 100000 males and from 2.8 to 4.29 per 100000 females (4).

In spite of progress in the medical and scientific fields, CRC concomitantly presents a significant economic burden 
worldwide. The economic impact of CRC in the United States was estimated to range between 5.5 billion and 6.5 billion United States dollars (US\$) in 2000, with inpatient costs representing $80 \%$ of total direct costs (7).

Although a progressive incidence of CRC has been demonstrated in Brazil, it is unknown how the current strategy of population screening for an early diagnosis and the availability of new and more effective chemotherapeutic agents affect nationwide hospitalization patterns for CRC. In addition, there are no studies on inpatient direct costs related to this disease in the Brazilian Public Health System. It is essential to measure these costs in order to estimate the CRC economic burden at a national level. Therefore, the objectives of this study were to determine rates and recent trends of hospital admissions for CRC in the Brazilian Public Health System between 1996 and 2008 and to assess the direct economic costs resulting from these admissions.

\section{MATERIALS AND METHODS}

\section{Data sources}

All data were extracted from the Hospital Information Systems of the Brazilian Unified Health System (SIH-SUS), which is maintained by DATASUS, the national agency for health statistics. SIH-SUS is a public nationwide database that comprises almost $80 \%$ of all hospital admissions in Brazil (8); it is the only public nationwide source of information on hospital morbidity and mortality. SUS is a subsystem of the National Health Care System, which consists of all health care centers financed by public providers. Thus, data from the other subsystem (the supplementary medical system, which consists of health plans and private patients) were not computed.

\section{Collected data}

All hospital admissions between 1996 and 2008 with a primary diagnosis of CRC were included. The CRC cases were identified by International Classification of Diseases (ICD) codes from the ninth and tenth revisions. The SIH-SUS database used the ICD-9 coding system until 1997; then the ICD-10 codes were adopted. Colon cancer (C18-C19) included cancers of the rectosigmoid junction; rectum cancer (C20-C21) included cancers of the rec- tum and the anal canal, excluding those originating in the skin of the anal region.

Although the SIH-SUS database includes data since 1984, more accurate parameters for diagnosis registration were not introduced in hospital admission systems until 1995 (9); hence, only data registered after 1996 are included in this study. The following variables were evaluated: gender, age, overall costs, costs per episode of hospital admission, mean length of stay per admission, and number of in-hospital deaths.

The age-stratified hospitalization rates were calculated by dividing the number of hospital admissions due to CRC for each year and age group by the size of the corresponding Brazilian population in each age group, obtained from the 2000 Brazilian census of The Brazilian Institute of Geography and Statistics (10); the resulting rates were multiplied by 100000 to obtain data expressed per 100000 persons per year. Age-standardized hospitalization rates were calculated by the direct method using the world standard population (modified by Doll et al. [11]).

The direct economic costs related to CRC hospital admissions reported in this study are based on the amount that SUS pays for each hospitalization, including all the specific costs of a hospital stay, such as complementary examinations, interventions and surgical procedures, medications (e.g., chemotherapy), and professional fees. These values were adjusted monthly for inflation according to Brazil's official inflation index from January 1996 until December 2008. These data were then converted from national currency (Brazilian real, BRL) to US\$ using the 2007 purchasing power parity (PPP) conversion factor to the official exchange rate ratio from the United Nations Statistics Division (12), which was the most recent available at the time of this writing. We assumed that the 2008 PPP conversion factor remained stable with respect to 2007 (1 PPP US\$ $=1.6$ BRL). Comparisons based on market exchange rates can lead to misinterpreted results because these rates are more susceptible to short-term variations and influences that often do not represent real long-term trends. PPP conversions, on the other hand, enable large equivalent economic comparisons across distinct countries (13).

\section{Statistical analysis}

All data were analyzed with SPSS 15 software (SPSS Inc., Chicago, United
States of America). Data used for this study comprise all CRC admissions in the Brazilian Public Health System. Therefore, descriptive rather than inferential statistics were used in the analysis. Increasing or decreasing trends of admission rates over time were assessed by the absolute change in percentage of the studied variables.

\section{Ethical aspects}

This study was approved by the local Institutional Ethics Committee and was done in accordance with the Declaration of Helsinki of the World Medical Association.

\section{RESULTS}

The SIH-SUS database identified 297108 hospital admissions for CRC between 1996 and 2008. The total hospital admissions increased $173 \%$ in the study period, from 12821 admissions in 1996 to 35040 in 2008 (Figure 1). Gender distribution revealed a relatively stable male/female ratio for the 1996-2001 period, with a slight female predominance $(\mathrm{male} /$ female ratio $=$ 0.95:1.0); from 2002 onward, a slight male predominance was noted until 2008 (1.06:1.0), when a female predominance was again observed (0.96:1.0) (Figure 1).

Hospitalization rates stratified by age demonstrated increasing trends for all age groups during the period (Figure 2). The highest rates were observed in the 70 - to 79-year age range (ranging from 47.9 per 100000 in 1996 to 117.4 per 100000 in 2008 for a $145 \%$ increase); for the 60- to 69- and > 80-year age groups, the hospitalization rates rose from 37.0 and 41.4 per 100000 to 90.7 and 101.3 per 100 000, respectively. The highest percent increase occurred in the $<40$ - and 50- to 59-year age groups, from 2.1 and 18.0 to 6.7 and 57.2 per 100000 for $210 \%$ and $217 \%$ increases, respectively.

The age-standardized hospitalization rates increased from 8.7 per 100000 in 1996 to 23.56 per 100000 in 2008, representing a striking rise of $171 \%$. The largest increase occurred between 2001 and 2002, from 9.4 to 15.31 per 100000 (a $63 \%$ increase).

The average length of hospital stay for CRC patients has decreased from 11.6 days in 1996 to 7.5 days in 2008. The average hospital mortality for CRC de- 
FIGURE 1. Number of hospital admissions for colorectal cancer and percentage distribution by gender, Hospital Information Systems of the Brazilian Unified Health System, Brazil, 1996-2008
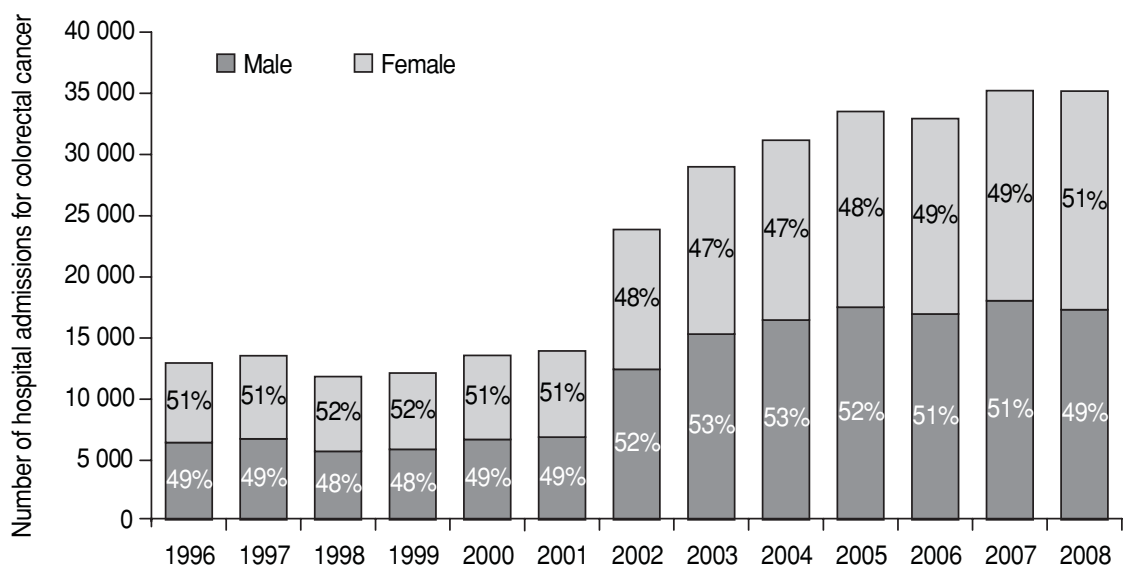

Year

creased from $10.4 \%$ in 1996 to $8.5 \%$ in 2008; when stratified by age, however, in-hospital mortality rates remained relatively stable for all age groups except for the < 40-year age group $(6.6 \%$ in 1996 and $2.9 \%$ in 2008 for a $56 \%$ relative decrease). As would be expected, the higher mortality rates were observed in the patients older than 80 years $(22.9 \%$ in 1996 and $22.1 \%$ in 2008) (Figure 3).

With respect to economic burden, the inflation-adjusted total charges attributable to CRC hospitalizations have grown 103\%, from US\$ 16.5 million in 1996 to US\$ 33.5 million in 2008 (Figure 4). When the average hospital charge per CRC admission was analyzed, however, a decreasing trend was observed over the period, declining from US\$ 1283 in 1996 to US\$ 954 in 2008 (Figure 4).

\section{DISCUSSION}

Colorectal cancer remains a major clinical and public health issue on a global scale. Currently, the highest incidence rates of CRC are observed in Europe, North America, and Oceania; the lowest rates are reported in Asia, Africa, and South America (14). In the United States, the incidence of CRC among men declined by $2.8 \%$ per year from 1998 to 2005 and among women it declined by $2.2 \%$ per year in the same period (15). By contrast, newly developed countries, such as the Czech Republic, have been presenting

FIGURE 2. Age-stratified hospital admission rates (per 100000 persons) for colorectal cancer, Hospital Information Systems of the Brazilian Unified Health System, Brazil, 1996-2008

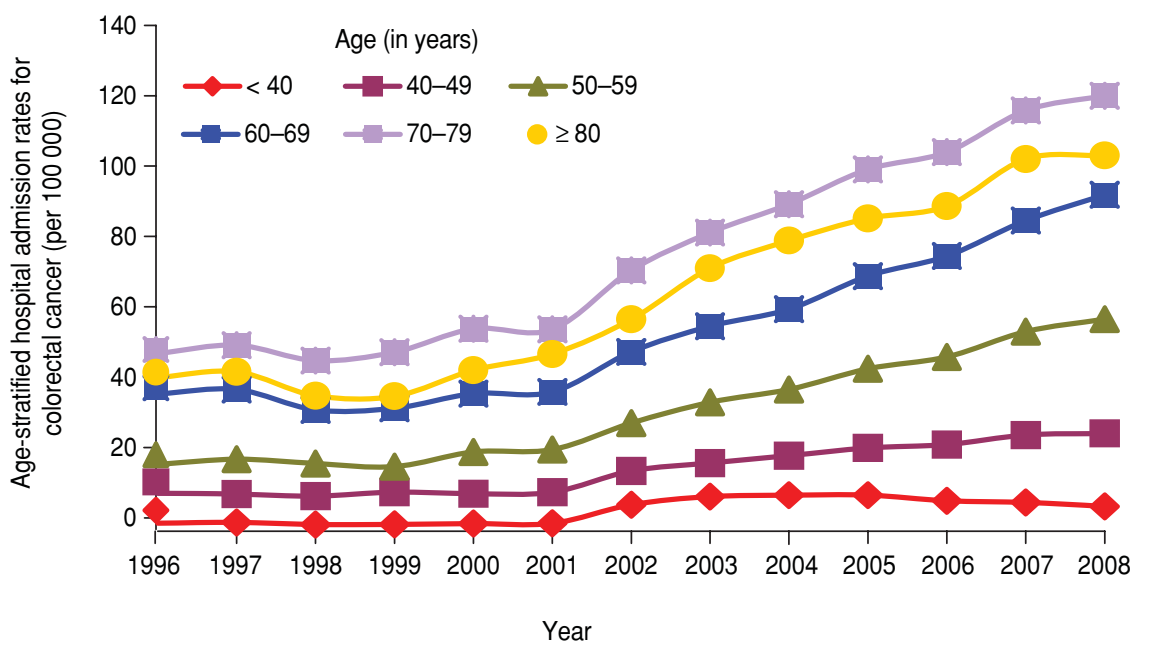

elevated and increasing incidence rates, probably due to "westernization" of the lifestyle in these countries (14).

In Brazil, the incidence of CRC varies remarkably among distinct geographic areas as a function of differences in socioeconomic patterns, risk factor exposure profiles, and availability of medical and economic resources (6). Likewise, mortality from CRC has been rising in Latin America (14, 16), although the mortality rates remained below 10 per 100000 in most countries of the region until 2000 (16). Trends in CRC mortality are unfavorable in Brazil, mainly due to modifications in national dietary and lifestyle habits; the prevalence of obesity, for example, has increased significantly over the last 20 years in three nationwide surveys (17).

In contrast, in the United States, deaths due to CRC have declined almost $9 \%$ over a 15 -year period $(18,19)$. Screening strategies, early detection, advances in prevention, and improved treatment with new chemotherapeutic regimens have resulted in an overall 5-year survival rate of $65.2 \%$ in that country. In Brazil, overall 5year relative survival rates of $33.1 \%$ in men and $32.7 \%$ in women with CRC were found according to a worldwide population-based study (20).

To the best of our knowledge, this is the first study to show an increase in hospitalization rates for CRC in the Brazilian Public Health System. On the other hand, according to data from the US Agency for Healthcare Research and Quality, there were almost 571700 hospitalizations in 2006 related to CRC in the United States (191.4 per 100000 persons), of which about one-quarter (151 900) had a principal diagnosis of CRC (50.8 per 100000 persons) (21). In addition, the rate of hospital admissions for CRC decreased almost $15 \%$ between 1995 and 2006 in that country (21). Although these numbers cannot be compared in absolute terms because of the different methodologies used in each study, they provide important parameters to illustrate different trends in hospital admissions for these countries.

The temporal trends in CRC hospitalizations reported in this study can be partly explained by nationwide increases in the incidence of CRC. Increasing incidence trends can also reflect better screening policies. Although Brazil still needs to consolidate a nationwide integrated cancer-screening program for 
FIGURE 3. Hospital mortality rates (percent) for colorectal cancer stratified by age groups, Hospital Information Systems of the Brazilian Unified Health System, Brazil, 1996-2008

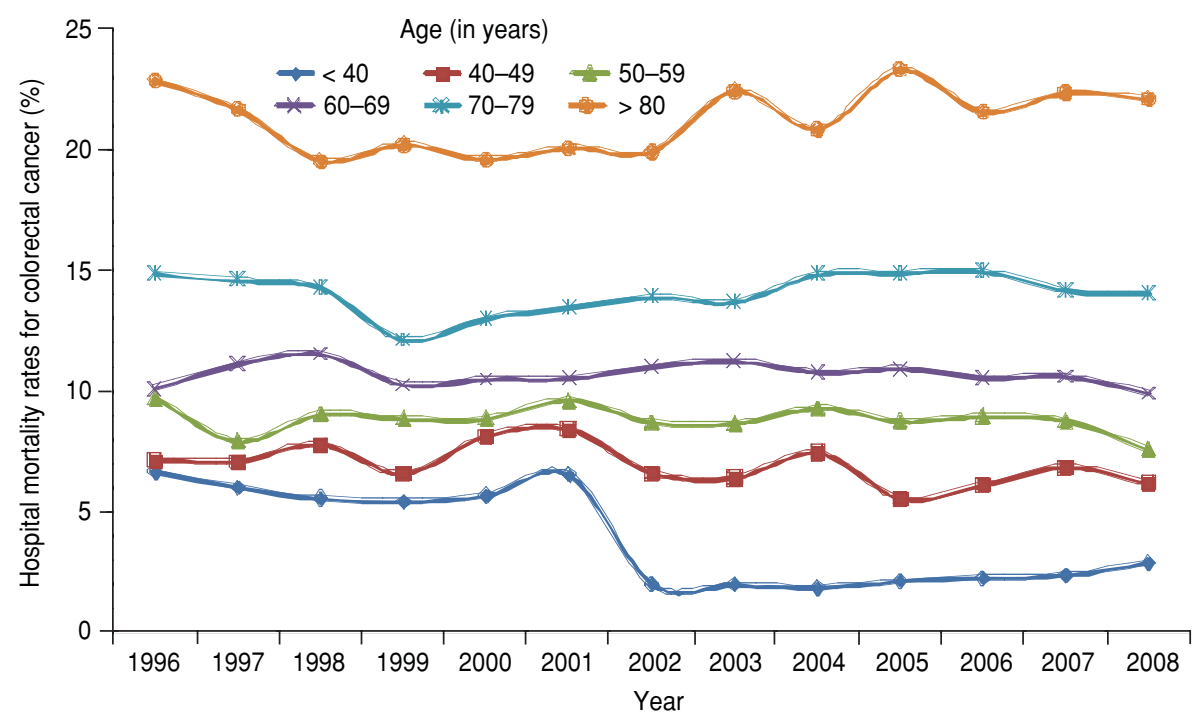

CRC, diagnostic tests have gradually become more widely available in the Public Health System (6).

Regarding age, the highest age-stratified hospitalization rates were observed in patients older than 60 years; in absolute percent terms, however, only $41 \%$ of the hospital admissions occurred in this age group between 1996 and 2008; in contrast, most hospitalizations principally for CRC in the United States in 2006 occurred in patients older than 65 years (62.3\%) (21). Given that CRC is predominantly a disease of older individuals, the aging of Brazil's population probably will be accompanied by an in- creased incidence of CRC cases. By the year 2030, the population age 65 or older will account for about $13.3 \%$ of the Brazilian population. Currently, this age group represents $6.9 \%$ of the total population (22). Furthermore, population aging probably has an important role in the economic and epidemiologic impacts of CRC screening (23).

Despite the significant increase in the total charges for CRC admissions between 1996 and 2008, the number of total admissions has increased in the same manner, which might have contributed to the decreasing trends observed in the mean hospital charge per admission.

FIGURE 4. Overall costs and mean charge for colorectal cancer admission, Hospital Information Systems of the Brazilian Unified Health System, Brazil, 1996-2008

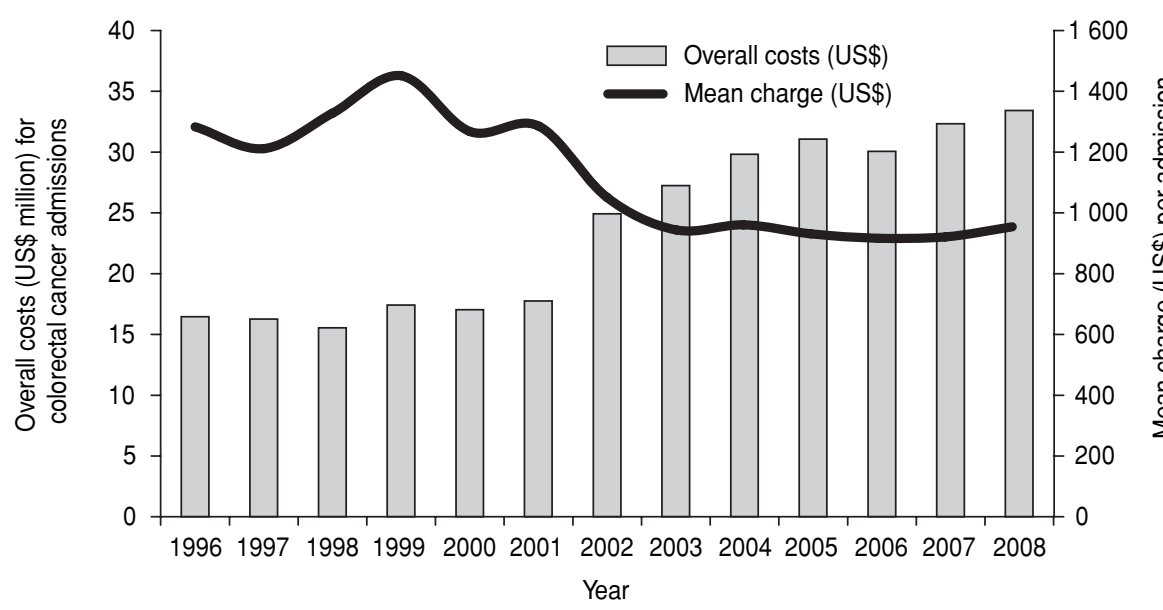

This trend may denote that financial resources allocated for CRC hospitalizations are insufficient to support the growing admission rates. On the other hand, a decreasing mean hospital charge per admission could be partially explained by the decreased mean length of stay.

Because the total economic impact for CRC has not been studied in Brazil, the percentage that hospitalization charges represent in CRC overall costs is unknown. Nevertheless, the economic costs of CRC admissions in Brazil are notably low when compared with those reported by more developed countries, even when adjusted for international economic variations using the PPP conversion factor; this observation probably can be extended to the CRC total economic costs.

Although the average mortality during hospitalization changed significantly over time, this effect seems to be attributable mainly to the decrease occurring in the age group below 40 years; age stratification did not disclose a significant decrease in CRC hospital mortality rates for the other age groups. In fact, the average hospital mortality rates for CRC remain substantially high in Brazil. In 2006, for example, hospital mortality for CRC in Brazil was $8.3 \%$, while a $4.5 \%$ rate was reported in the United States (21).

Possible limitations of the study concern the accuracy of the SIH-SUS data, which may be affected by imprecise information registered on medical records and by the fact that the principal diagnosis may be selected based on the amount the Public Health System will pay for it $(24,25)$. Data obtained from large government databases are also limited because of the variability of information provided by each health care center, the lack of clinical information, and the heterogeneity in the quality of health care among distinct areas of the country. Moreover, as it is unknown how specifically the CRC admissions registered in the SIH-SUS databank represent overall CRC admissions in Brazil, another limitation of this study relates to representativeness of the data. It is known, however, that to some degree SUS partly finances high-complexity procedures for private patients (26), such as oncologic treatment; therefore, the SIHSUS databank may also include data from private patients.

In conclusion, this study demonstrated that hospitalization rates for CRC 
in the Brazilian Public Health System significantly increased between 1996 and 2008. Furthermore, these data provide an insight into the increasingly significant economic impact of colorectal cancer admissions to the health system.

1. Boyle P, Levin B, eds. World cancer report 2008. Lyon, France: IARC Press; 2008.

2. Parkin DM, Bray F, Ferlay J, Pisani P. Global cancer statistics, 2002. CA Cancer J Clin. 2005;55:74-108.

3. Instituto Nacional de Câncer. Estimativa 2008: incidência de câncer no Brasil. Rio de Janeiro: INCA; 2007.

4. Habr-Gama A. Colorectal cancer: the importance of its prevention. Arq Gastroenterol. 2005;42:2-3.

5. das Neves FJ, Mattos IE, Koifman RJ. Colon and rectal cancer mortality in Brazilian capitals, 1980-1997. Arq Gastroenterol. 2005;42: 63-70

6. Reis RS, Santos MO, Bloch KV. Colorectal cancer in Porto Alegre and Fortaleza, Brazil: incidence trends and distribution pattern from 1990 to 1999. Cad Saude Publica. 2009; 25:1046-53.

7. Redaelli A, Cranor CW, Okano GJ, Reese PR. Screening, prevention and socioeconomic costs associated with the treatment of colorectal cancer. Pharmacoeconomics. 2003;21: 1213-38.

8. Bittencourt SA, Camacho LA, Leal MC. Hospital Information Systems and their application in public health. Cad Saude Publica. 2006;22: 19-30.

9. DATASUS. Informações de Saúde. Notas técnicas: morbidade hospitalar do SUS por local de internação. Available from: http:// tabnet.datasus.gov.br/cgi/sih/midescr.htm. Accessed 8 November 2009.

10. Instituto Brasileiro de Geografia e Estatística. Demographic Census 2000. Resident population, by urban or rural household, by age
Further studies are necessary to determine the epidemiology and the total economic costs of CRC in Brazil. A possible way to improve both the quantity and the quality of information nationally on the epidemiology of CRC could be to

\section{REFERENCES}

groups-Brazil. Available from: http:// www.ibge.gov.br/english/estatistica/popu lacao/censo2000/tabelabrasil111.shtm. Accessed 6 November 2009.

11. Doll R, Payne P, Waterhouse JAH. Cancer incidence in five continents: a technical report. Vol. I. Berlin: Springer-Verlag; 1966.

12. United Nations Statistics Division. Purchasing power parities (PPP) conversion factor, local currency unit to international dollar (last updated: 14 July 2009). Available from: http://mdgs.un.org/unsd/mdg/SeriesDe tail.aspx?srid=699. Accessed 23 November 2009.

13. The World Bank. International Comparison Program: PPP and exchange rates. Available from: http://go.worldbank.org/YVRZD KSAT0. Accessed 18 November 2009.

14. Center MM, Jemal A, Smith RA, Ward E. Worldwide variations in colorectal cancer. CA Cancer J Clin. 2009;59:366-78.

15. Jemal A, Thun MJ, Ries LA, Howe HL, Weir HK, Center MM, et al. Annual report to the nation on the status of cancer, 1975-2005, featuring trends in lung cancer, tobacco use, and tobacco control. J Natl Cancer Inst. 2008;100: 1672-94.

16. Bosetti C, Malvezzi M, Chatenoud L, Negri E, Levi F, La Vecchia C. Trends in cancer mortality in the Americas, 1970-2000. Ann Oncol. 2005;16:489-511.

17. Monteiro CA, $\mathrm{D}^{\prime} \mathrm{A}$ Benicio $\mathrm{MH}$, Conde $\mathrm{WL}$, Popkin BM. Shifting obesity trends in Brazil. Eur J Clin Nutr. 2000;54:342-6.

18. Jemal A, Siegel R, Ward E, Murray T, Xu J, Thun MJ. Cancer statistics, 2007. CA Cancer J Clin. 2007;57:43-66. create an independent database supported by multiple cancer care reference centers from all geographic regions of the country. This would enable a more accurate assessment of costs related to this disease in Brazil.
19. Boring CC, Squires TS, Tong T. Cancer statistics, 1992. CA Cancer J Clin. 1992;42:19-38.

20. Coleman MP, Quaresma M, Berrino F, Lutz JM, De Angelis R, Capocaccia R, et al. Cancer survival in five continents: a worldwide population-based study (CONCORD). Lancet Oncol. 2008;9:730-56.

21. Russo CA, Stocks C. Hospitalizations for colorectal cancer, 2006. HCUP Statistical Brief 69. Available from: http://www.hcupus.ahrq.gov/reports/statbriefs/sb69.pdf. Accessed 21 November 2009.

22. Instituto Brasileiro de Geografia e Estatística. Projeção da População do Brasil por Sexo e Idade para o período 1980-2050-Revisão 2008. Available from: http://www.ibge. gov.br/home/estatistica/populacao/proje cao_da_populacao/2008/piramide/ piramide.shtm. Accessed 15 December 2009.

23. Macafee DA, Waller M, Whynes DK, Moss S, Scholefield JH. Population screening for colorectal cancer: the implications of an ageing population. Br J Cancer. 2008;99:1991-2000.

24. Mathias TA, Soboll ML. Reliability of diagnoses on authorization forms for hospital admission. Rev Saude Publica. 1998;32:526-32.

25. Veras CM, Martins MS. Reliability of data from authorization forms for hospital admittance, Rio de Janeiro, Brazil. Cad Saude Publica. 1994;10:339-55.

26. Coelho IB. Deadlocks in the Brazilian National Health Care System. Ciên Saúde Colet. 2007;12:309-11.

Manuscript received on 12 April 2010. Revised version accepted for publication on 3 August 2010.
RESUMEN

Aumento de las tasas de ingresos hospitalarios por cáncer colorrectal y su carga económica en Brasil, 1996-2008

Palabras clave
Objetivo. Determinar las tendencias de las tasas de ingresos hospitalarios por cáncer colorrectal (CCR) en el sistema de salud pública brasileño de 1996 al 2008 y evaluar sus costos económicos.

Métodos. Se utilizó la información de la base de datos de los sistemas de información de los hospitales del Sistema Único de Salud brasileño con objeto de analizar todos los ingresos con diagnóstico primario de CCR entre 1996 y el 2008.

Resultados. Durante el período de estudio, se produjeron 297108 ingresos por CCR, con un aumento anual de 12821 en 1996 a 35040 en el 2008. Las tasas de ingresos estandarizadas según la edad aumentaron de 8,7 a 23,56 por 100 000, con un aumento porcentual de 171\%. La estancia hospitalaria media disminuyó de 11,6 días en 1996 a 7,5 días en el 2008. La mortalidad hospitalaria promedio descendió de 10,4\% a 8,5\%. Los costos de las hospitalizaciones por CCR aumentaron de US\$16,5 millones en 1996 a US\$33,5 millones en el 2008; el costo promedio de cada ingreso, sin embargo, disminuyó de US\$1 283 a US\$954.

Conclusiones. Las tasas de hospitalización por CCR en Brasil han aumentado significativamente a lo largo de un período de 13 años y han acarreado un considerable incremento de la carga económica ajustada según la inflación; las tasas nacionales de mortalidad hospitalaria se han mantenido relativamente elevadas.

Neoplasias colorrectales; hospitalización; tiempo de internación; mortalidad hospitalaria; costos de hospital; Brasil. 